\title{
Logic for morals, morals from logic
}

\author{
Charlie Kurth
}

Published online: 20 May 2010

(C) The Author(s) 2010. This article is published with open access at Springerlink.com

\begin{abstract}
The need to distinguish between logical and extra-logical varieties of inference, entailment, validity, and consistency has played a prominent role in metaethical debates between expressivists and descriptivists. But, to date, the importance that matters of logical form play in these distinctions has been overlooked. That's a mistake given the foundational place that logical form plays in our understanding of the difference between the logical and the extra-logical. This essay argues that descriptivists are better positioned than their expressivist rivals to provide the needed account of logical form, and so better able to capture the needed distinctions. This finding is significant for several reasons: First, it provides a new argument against expressivism. Second, it reveals that descriptivists can make use of this new argument only if they are willing to take a controversial—but plausible-stand on claims about the nature and foundations of logic.
\end{abstract}

Keywords Expressivism - Logical consequence · Logical validity ·

Logical form

The need to distinguish between logical and extra-logical varieties of inference, entailment, validity, and consistency has played a prominent role in meta-ethical debates between expressivists and descriptivists. These intuitive distinctions are not of mere theoretical interest: We take logical inferences to have a privileged place in thought and inquiry; we see logical errors as involving a special type of failing and as inviting a distinctive sanction. So it's important that we be able to explain what distinguishes these logical notions from their extra-logical counterparts. The

C. Kurth $(\bowtie)$

Department of Philosophy, University of California, San Diego, 9500 Gilman Drive, 0119, La Jolla, CA 92093, USA

e-mail: ckurth@ucsd.edu 
standard explanation is familiar: Logical consequences, for instance, are truth preserving in the sense that-no matter what interpretations we give to the extralogical vocabulary - they will not lead from true premises to false conclusions. But this standard explanation is not available to expressivists. Unlike descriptivists, expressivists reject truth-conditional accounts of the meanings of normative sentences. Moreover, expressivists acknowledge that this move has consequences: ${ }^{1}$ they grant that if they're to capture the intuitive distinction between these important logical and extra-logical notions, they must provide an alternative to the standard, truth-centric explanation. ${ }^{2}$ However, the plausibility of the proposed alternatives is deeply contested. ${ }^{3}$

While this traditional debate has drawn out important and interesting challenges to the expressivists' program, it overlooks a deeper and more significant issue. For notice, not only is the standard explanation of logical consequence framed in terms of the preservation of truth, but it also assumes that we can distinguish the logical terms from the extra-logical ones. That is, it presumes we have an account of logical form. To date, questions of logical form have not been part of debates between expressivists and descriptivists. ${ }^{4}$ That's a mistake. For one, questions of logical form are, in an important sense, prior to questions concerning the preservation of truth: Logical consequences are truth-preserving in virtue of their logical form; it's logical form that guarantees that true premises won't lead to a false conclusion. ${ }^{5}$ Therefore, any complete account of logical consequence-truth-centric or expressivist-must include an account of logical form that explains why logical consequences carry this guarantee. Moreover, we shouldn't just assume that a viable account of logical form can be given, for it is controversial whether descriptivists-much less expressivists - can provide a principled account of logical form. ${ }^{6}$

But once we recognize the importance that matters of logical form have for our understanding of logical consequence, we see that it will likely have implications

\footnotetext{
${ }^{1}$ See, for instance, Blackburn (1984, pp. 189-196, 1988, 1998, p. 72), Gibbard (1990, Chap. 5, 2003, Chaps. 3-4), and Horgan and Timmons (2006, pp. 277-282).

${ }^{2}$ By "truth-centric explanation" I mean explanations that make use of substantive (i.e., non-deflationary) accounts of truth. Against Horwich (1994, 1998), I follow Dreier (1996), Gibbard (2003), Horgan and Timmons (2006) (among others) in holding that an appeal to a deflationary account of truth is insufficient as the basis for an expressivist account of logic and inference.

${ }^{3}$ Since the problems with the expressivists' alternative accounts of logic and inference (often lumped together under the label "the Frege-Geach problem") are familiar, I will merely mention some of the more prominent ones - expressivism cannot provide a viable account of negation, it can't make sense of normative content in embedded contexts, it conflates failures of logical reasoning with more general failures of rationality. For a sampling of the representative arguments, see Hale (1993), Schueler (1988), Wright (1988), van Roojen (1996), and Unwin (2001).

${ }^{4}$ This may be too strong: the arguments of Hale (1993) and van Roojen (1996) seem to raise concerns in the vicinity of this second feature of logical consequence.

${ }^{5}$ On this point, see Tarski (1935), Etchemendy (1990), Sainsbury (1991), Sher (1991), and MacFarlane (2005), among others.

${ }^{6}$ Tarski, in his seminal paper on logical consequence, both noted that his account relied crucially on a division of logical and extra-logical vocabulary, and expressed unease about the possibility of a principled demarcation (1935, pp. 418-419; c.f., 1986). Others-e.g., Etchemendy (1990)-are more thoroughly skeptical. Also, though most logicians endorse a truth-centric account of the meanings if logical terms, there are some (e.g., Brandom 2001) that pursue "expressivist" alternatives.
} 
for debates between expressivists and descriptivists. For one, it points to a new way of assessing the adequacy of the expressivists' alternative account of logical consequence: in addition to asking if their proposals are truth-preserving, we can also ask if they are grounded in a principled account of logical form. Yet recognizing the importance of logical form also has implications for descriptivists. In light of the above, we can now see that the traditional descriptivist arguments against expressivist accounts of logic have force only if descriptivists themselves can provide a principled account of logical form. ${ }^{7}$

In what follows, I will argue that descriptivists are better positioned than their expressivist rivals to provide the needed account of logical form, and so better able to capture the intuitive distinction between logical consequences and extra-logical ones. This conclusion is significant for several reasons: First, it provides a new argument against expressivism—one that demonstrates that even recent, sophisticated proposals for an expressivist-friendly account of logical consequence fall short. ${ }^{8}$ Second, we will see that descriptivists can make use of this new argument (and also substantiate their traditional objections) only if they are willing to take a controversial-but, I will argue, plausible—stand on claims about the nature and foundations of logic. The general moral is that debates between expressivists and descriptivists are much more closely tied to questions about logic than has been commonly thought.

\section{Background: logical consequence and logical form}

To understand why expressivists face a special problem in making sense of logical consequence, we need a better understanding of what it means to say that logical consequences are determined by logical form. ${ }^{9}$ As we will see, the standard explanation holds that logical consequences are valid solely in virtue of the meanings of their logical terms: logical terms specify the underlying form of logical consequences, the having of which guarantees that their conclusions follow from their premises. A closer look at this explanation of the relationship between logical form and logical consequence will allow us to formulate a general and intuitive constraint - a modal test - that any viable account of logical consequence must meet.

\subsection{The importance of logical form}

Philosophers of logic note two distinctive features of logical consequences. Most obviously, logical consequence relations are formal in the sense that they are determined solely by the structure or form-not the content-of the sentences involved: Intuitively, it's in virtue of form alone that the conclusion 'someone drank

\footnotetext{
7 See, for instance, the citations in footnote 3.

${ }^{8}$ E.g., Horgan and Timmons (2006, pp. 288-297), and Schroeder (2008, Chap. 5).

9 For simplicity, I will focus for the most part on logical consequence-though what I say applies with equal force to related logical notions.
} 
the beer' follows from the premise 'Bob drank the beer.' By contrast, extra-logical consequence relations are not purely formal-the validity of extra-logical inferences relies on the substantive content of the sentences involved: the conclusion 'beer is made of water' follows from premise 'beer is made of $\mathrm{H}_{2} \mathrm{O}$ ' because of what terms like 'water' and ' $\mathrm{H}_{2} \mathrm{O}$ ' mean. Moreover, which terms we identify as contributing to the form (rather than content) of a sentence matters: The terms we identify as logical-and so formal-determine which inferences we count as logical consequences. For instance, we take 'someone' to be a logical term. That we do this helps explain why

(1) someone is loud and rowdy

is a logical consequence of

(2) Bob is loud and Bob is rowdy.

But it also explains why (1) is not a logical consequence of

(3) someone is loud and someone is rowdy.

This is significant: the terms that we take to be constitutive of logical form determine what counts as a logical consequence; this means that we need a principled way of identifying which terms are the logical terms.

Enter necessity. Philosophers of logic take the second distinctive feature of logical consequences to be that they are guaranteed to be truth preserving. Witness John Etchemendy:

The most important feature of logical consequence, as we ordinarily understand it, is a modal relation that holds between implying sentences and sentences implied. ... [The] conclusions [of logically valid arguments] are said to "follow necessarily" from their premises. (1990, p. 81)

Given the significance of this guarantee to our understanding of logical consequence, philosophers of logic have traditionally taken the correct selection of logical terms - and so the correct specification of logical form-to be the one that captures this distinctive necessity. ${ }^{10}$

\subsection{The modal test}

Combining these two features-formality and necessity-points to a general constraint on any plausible account of logical form: A viable account must specify a set of logical terms that captures the guarantee we associate with logical consequences. But if we're to make use of this constraint, we need to know more about the guarantee. Intuitively, logical consequences are strongly counterfactually stable: they continue to hold in a world $w$ even in the face of alterations to what is (say) nomologically or metaphysically possible in $w$. By contrast, extra-logical consequence relations exhibit lesser degrees of counterfactual stability. This

\footnotetext{
${ }^{10}$ On the nature of the formality and necessity of logical consequence, see for instance Tarski (1935), Sher (1991, Chap. 3), Etchemendy (1990), and Sainsbury (1991, Chaps. 1, 6).
} 
conclusion is well supported by our modal intuitions. ${ }^{11}$ For instance, we take logic to be more basic than things like science, psychology, and metaphysics in the following sense: what's logically possible does not seem to depend on things like what is scientifically, psychologically, or even metaphysically possible. Moreover, a converse dependency does not hold. ${ }^{12}$ We also take worlds where the facts of logic are different-e.g., worlds where disjunctive syllogism is not a valid inference schema-to be more remote (if there even are such worlds) than worlds where the extra-logical facts are different-e.g., worlds where objects can move faster than the speed of light, or where reddish-green things are just as common as bluish-green ones. In fact, we can explain why we have these intuitions in a way that deepens our understanding of why logical consequence has the distinctive modal profile that it does: Logic is both our most general mode of inquiry, and is "topic-neutral" in the sense that it does not depend on facts about things like science, psychology, and (much of) metaphysics. It is because of these features-generality and neutralitythat logical consequence has its distinctly stable modal profile.

Given this account of the modal features of logical consequence, we can formulate a substantive constraint on any viable theory of logic form:

The modal test: A viable theory must explain what it is about logical form that provides logical consequences with their distinctive modal stability.

With this test in hand, we're positioned to see both why expressivists have difficulties providing an account of logical consequence, and how descriptivists can avoid them.

\section{Meta-ethics and the modal test}

At this point, one might think that meeting the modal test is a problem in the philosophy of logic, not a problem in meta-ethics. But that would be a mistake. Though they may not realize it, both expressivists and descriptivists are-by their own lights-committed to meeting the modal test. As we've noted, expressivsts acknowledge that the plausibility of their accounts requires that they be able to capture the "mighty "musts' of logic." 13 But, as the discussion so far reveals, the characteristic feature of these "musts" lies in the distinctive guarantee that they carry - their uniquely stable modal profile. This means that capturing what's special about (say) the "musts" of logical consequences will require expressivists to meet the modal test. But descriptivists face the same requirement. The importance of this point has not been appreciated: the traditional descriptivist critiques of expressivist accounts of logic presume that a viable, descriptivist response to the modal test can be provided. But that's an assumption that we-and especially the expressivists-

\footnotetext{
11 Tarski emphasized the importance of our ordinary intuitions for philosophical accounts of logical consequence: "Certain considerations of an intuitive nature will form our starting-point" (1935, p. 414). Also see Sher (1991, Chap. 3) and Etchemendy (1990, Chap. 6).

12 The claim in the text is meant to be restricted to the non-logical aspects of metaphysics.

13 The quote is from Blackburn (1998, p. 72), but also see his (1984, pp. 189-196) and (1988) as well as Gibbard (1990, Chap. 5, 2003, Chaps. 3-4) and Horgan and Timmons (2006, pp. 277-282).
} 
should challenge. ${ }^{14}$ In light of all this, it is surprising that existing debates between descriptivists and expressivists on matters of logic and inference have overlooked the importance of questions of logical form. ${ }^{15}$

At this point one might worry that the modal test places an excessive demand on expressivists: given that expressivists acknowledge that they're providing an alternative account of logic and inference, demanding that they follow the standard procedure of grounding an account of logical consequence in an account of logical form just asks too much. ${ }^{16}$ This concern would be legitimate were the modal test to require a truth-centric account of logical form. But it doesn't. It merely requires an account of logical form - truth-centric or otherwise-that captures the distinctive modal stability that we associate with logical consequences. Granted, because of the expressivists' self-imposed prohibitions on the use of robust notions of truth, satisfaction, and the like, they have fewer resources from which to explain this stability (more on this below). But the conclusion that they cannot develop a viable account isn't built into the test itself. Moreover, as we will see, there is a substantial tradition in the philosophy of logic that maintains - in line with the expressivists' foundational commitments - that the necessity of logic is grounded in basic features of thought.

In sum, the modal test provides us with a new way of assessing debates between expressivists and descriptivists. Whereas the traditional debates focused on whether expressivists could provide an account of logic that was truth-preserving, the modal test asks both expressivists and descriptivists to explain what philosophers of logic take to be the most significant feature of logical (as opposed to extra-logical) consequences - namely, their distinctive modal stability.

\section{The limits of expressivism}

To assess expressivists' ability to meet the modal test, we must say a little more about expressivism. First, expressivism is, at its core, a thesis about the nature of thought. It holds that normative claims do not aim to describe the world, but rather express distinctive non-cognitive states of mind. So, in judging (say) that torture is wrong, one does not make an assertion about the way the world is; rather, one's speech-act is more like a cry of pain or a command to close the door. But since logic and reasoning are normative, the expressivist is committed to treating them in the

\footnotetext{
14 It's worth emphasizing that meeting the modal test is not a trivial task. There is significant debate among philosophers of logic regarding how-even whether-it can be done. For a representative sample, see Tarski (1935, pp. 418-410; 1986), Etchemendy (1990), Dummett (1991, pp. 54-55), Sainsbury (1991), Sher (1991), and MacFarlane (2005).

15 The assumption that there is a principled way of distinguishing between logical and extra-logical content is explicit in the recent expressivist accounts of logical consequence proposed by Horgan and Timmons (2006, pp. 288-297) and Schroeder (2008, pp. 69-70), and comes out in the work of Blackburn and Gibbard via their use of inference schemas. It is implicit in most descriptivist critiques.

16 Thanks to an anonymous referee for helping me see the need to explain why it's reasonable to demand that expressivists meet the modal test.
} 
same way. ${ }^{17}$ That is, they are committed to grounding an account of logic, not in some robust notion of truth or satisfaction, but rather in claims about the nature of certain mental states. ${ }^{18}$ Second, expressivists have a standard strategy for addressing charges that they cannot do something that their descriptivist rivals can: They determine how the problem is avoided within the descriptivist framework, and then provide an expressivist model that mimics it. ${ }^{19}$ So while philosophers of logic typically express their accounts of logical consequence and logical form in ways that make essential use of substantive notions like truth and satisfaction, we can use this strategy to develop expressivist-friendly versions that mimic these accounts.

There are two very general strategies that philosophers of logic have pursued in order to explain the characteristic guarantee of logical consequence. The first argues that logical form provides the underlying structure of thought and language: it's because logical form captures certain special features of thought and language that logical consequences must preserve truth. The second maintains that logical form is an abstract, extra-mental part of the world-it's in virtue of the fact that logical terms map to distinctive formal features of the world that logical consequences carry the guarantee that they do. ${ }^{20}$ Since strategies that look to thought and language are more in line with the expressivists' framework, let's start by taking a closer look at them.

\subsection{Appeals to the nature of thought and language: version 1}

One way to flesh out the details of the first strategy is by following Davidson and Quine. $^{21}$ Proposals of this sort take logical form to play an essential, structural role in a systematic account of the meaning of a given language. In particular, logical form is a way of regimenting the truth-functional relations of the sentences of a language so that the (basic) inferences that users of that language make are represented as truth preserving. To flesh this out, consider the following explanation of why I took the cab to the airport rather than the bus: I believed that I could only get to the airport by cab or by bus; I believed that a bus would not get me there as quickly as a cab; and I wanted to get to the airport as soon as possible. Butimportantly_this account gets its explanatory power by representing my decision

\footnotetext{
17 A couple of points: (1) The normativity of logic and reasoning is not the only reason expressivists are committed to treating them non-descriptively. There is also, for instance, the problem of fitting non-truthconditional normative sentences within the standard, truth-conditional accounts of logic. (2) Hybrid views-views that seek to combine an expressivist account moral content with a traditional, truth-centric account of logic and inference-would reject the claim in the text that expressivism about (say) morality entails expressivism about logic. But they are not the concern of this essay. See Schroeder (2009) for an insightful discussion of different forms of hybrid views and a (largely) skeptical assessment of their viability.

18 See, for instance, Blackburn (1984, pp. 191-195, 1988, pp. 190-193), Gibbard (1990, pp. 98-102; 2003, pp. 62-63), Horgan and Timmons (2006, pp. 277-278), and Schroeder (2008, Chaps. 3-5).

19 See Gibbard (2003, p. 81) for a nice statement of this standard move.

20 Though this is not the standard way of parsing accounts of logical form (but see Sher 1999), I use it because it proves to be a particularly helpful way to explore the modal test with the context of expressivism and descriptivism.

21 See, for instance Davidson (1984) and Quine (1960, 1980).
} 
process as having the form of something like disjunctive syllogism. Furthermore, in order for this account to explain my decision to take the cab, two conditions must hold: (i) I must be understood as taking terms like 'or' and 'not' to have their standard meanings, and (ii) these logical terms have their standard meanings because that's how one represents my reasoning as truth-preserving.

This fact-namely, that these two conditions must hold in order for the above account to explain my decision to take the cab-could be used to explain the relationship between logical form and the distinctive necessity of logic in a way that meets the modal test: Logical form (as specified by the standard meaning postulates of 'or', 'not', and the like) articulates the formal features of thought that are essential to our capacity to think, speak, and act as we do. In short, this first proposal maintains that it is because these formal features must be in place if our reasoning is to be truth preserving that logical consequences have their distinctive necessity. ${ }^{22}$

In its canonical form, this strategy for meeting the modal test is built around robust semantic notions of truth and satisfaction. However, there is an expressivistfriendly alternative in the vicinity: rather than taking the correct account of logical form to be captured by what's necessary for the preservation of truth, the expressivist can take it to be that which is essential to our ability to think and act as the rational beings that we are. That is, rather than grounding the account in a substantive notion of truth, the expressivist relies on an account of rationality. ${ }^{23}$ More specifically, the idea is this: We are (generally) rational beings in the sense that our behavior is shaped and constrained by the systematic connections that hold between our beliefs, desires, and intentions. We also want a way of explaining, for instance, why I took the cab that-given my beliefs, desires, and intentions-takes my behavior to be rational. Getting such an account requires, among other things, that I be understood as taking 'or,' 'not,' and the like as having their standard meanings. So, as with the canonical versions of this strategy, the expressivistfriendly version takes logical form (as specified by the standard meaning postulates of 'or', 'not', etc.) to articulate the formal features of thought that are essential to our capacity to think, speak, and act as the rational beings that we are.

To see why the account of the distinctive necessity of logic that we get from this proposal fails to meet the modal test, let's begin by considering what it says about the nature of logical consequence. We can do this by returning to the cab vs. bus example. This example draws out that what counts as being rational is a function of,

\footnotetext{
${ }^{22}$ Notice that the argument in the text does not establish that the standard selection of logical terms is the only way to explain our reasoning as truth-preserving, and so does not (yet) explain why the formal features of language and thought must be as they are. Clearly an expressivist (or descriptivist) interested in pursuing this strategy would need to demonstrate that the standard selection of logical terms is the only way to secure a satisfactory explanation of our reasoning. In what follows, I will assume that the needed explanation can be provided.

23 Blackburn (1998, pp. 51-59, 68-75) and Gibbard (1990, pp. 99-102, 156-170) make use of roughly this line of reasoning to give an account of extra-logical content. It is unclear whether they would endorse the move in the text to apply the strategy to flesh-out their accounts of logical content as well. Regardless, they and Horgan and Timmons (2006, p. 278) have the resources to make a version of the argument that follows. However, an expressivist inclined toward this strategy needs to provide an account of rationality that is not cashed out in terms of truth-satisfaction or property exemplification. Both Blackburn (1998) and Gibbard (1990) make proposals. While I will not assess these here, see Sturgeon (1995) for concerns.
} 
among other things, the nature of our psychology; it's a function of the nature of the connections between our beliefs, desires, intentions, etc. But surely our psychological constitution could have been different. For instance, we could have been less responsive to psychological phenomenon like cognitive dissonance. ${ }^{24}$ If this were the case, we would be less "disturbed" when we found ourselves to be in mental states where we affirmed sets of judgments like $\{P$ or $Q$, not- $P$, not- $Q\}$, and so more likely to find ourselves in such states. But if we were largely unaffected by such dissonance, understanding our behavior as rational might require denying that logical terms like 'or' and 'not' map onto the standard rules of logic (i.e., the $\mathrm{v}$ and $\sim$ introduction/elimination rules); it might require denying that disjunctive syllogism counts as a legitimate formal inference. ${ }^{25}$

The implications of this possibility are significant. For one, because this proposal must ground the modal profile of the standard rules of logic in substantive claims about how human psychology happens to be, it makes the modal profile of these rules (and, therefore, the modal profile of logical consequence) a function of the modal profile of our psychology. So it commits the expressivist to the dubious claim that the modal stability of human psychology is on par with the modal stability of logical consequence. For similar reasons, the proposal also makes logical consequence dependent on contingent features of human psychology. These results entail that this proposal fails to meet the modal test-it cannot explain why the modal profile of logical consequence is distinct from, and more stable than, the modal profile of human psychology. ${ }^{26}$

\subsection{Appeals to the nature of thought and language: version 2}

If an appeal to a general interpretive constraint proves too weak to secure the distinctive necessity associated with logical consequence, expressivists might try to secure a stronger foundation by looking to versions of the first general strategy that take logical form to be the upshot of certain privileged rules of thought and reasoning. Philosophers of logic who have pursued this proposal identify the privileged set of rules with the most basic rules of inference-rules that are

\footnotetext{
${ }^{24}$ This is not implausible given the varying degrees of cognitive dissonance that social psychologists have found in their subjects. See, for instance, Aronson (1999).

25 Given the expressivists' commitment to naturalism, I see no way for them to deny this possibility. But presumably we're dealing with a conceptual issue here, and so can set questions of naturalism aside. Doing this allows us to consider more fanciful cases: Suppose that it is well known that an evil demon will put a malicious curse on us if we reason by disjunctive elimination. Under such circumstances, understanding our behavior as rational might again require denying that 'or' and 'not' have their standard meanings.

26 The expressivist strategy of grounding logic in an account of rationality faces further problems. van Roojen (1996) argues that it results in expressivists conflating logical consequences with rational consequences. Though van Roojen's argument is controversial (see, for instance, Gibbard (2003, pp. 7579)), the problem he identifies is on point: our notion of what's rational tracks something different than does our notion of what a logical consequence is. In fact, the modal test allows us to sharpen van Roojen's insight: we can now specify why a move to ground logic in rationality must fail—it lacks the resources needed to secure the distinctive modal profile of logical consequence and the like.
} 
universally applicable to judgment and inference. ${ }^{27}$ Furthermore, it seems that something like this idea can be found in Gibbard's (2003) proposal. ${ }^{28}$ Taking a closer look will help us see how an expressivist might develop it into a response to the modal test.

Gibbard focuses on the mental operations we employ when making practical decisions about what to do. The result of these operations is a complex, noncognitive mental state-something like a set of inter-related commitments. Following Gibbard, let's call this basic mental operation planning and the resulting mental state a plan. For the purposes at hand, plans and planning are interesting for several reasons. First, plans seem to involve certain formal features (or operations) essentially. For instance, I can combine parts of plans-I can combine my plan to go to the grocery with my plan to pick the kids up from school; I can reject plans-I can reject a plan for a 60th birthday party in my honor; I can make general plans-I can plan to vote for whichever Democrat wins the nomination. ${ }^{29}$ Second, the mental operations of planning that are essential features of plans appear to match up nicely with the formal features of logic. Witness Gibbard:

Combining, rejecting, and generalizing apply to mental operations [of planning], which then have content. The content is expressible with the logical operators of conjunction, negation, and quantification. These logical devices mirror the mental operations of combining, rejecting, and generalizing. ... Logic ... is a matter of the ways statements allow determinate possibilities and rule them out. The logical import of a statement, we can say, is a matter of [what] it allows and [what] it rules out. This gives us a way of thinking of the content of such judgments. (p. 58)

Given the context, it seems that by "content" Gibbard intends to refer to something like the meaning postulates (rules) standardly associated with 'and', 'not', and 'all'. So we could see Gibbard as suggesting that logical form merely regiments the foundational operations that underlie the basic non-cognitive mental operation of planning. This points to a possible response to the modal test: Logical consequences have their distinctive modal stability because logical form expresses a set of mental operations (the rules of logic) that are essential to planning; it's because these operations are essential to planning that logical consequence has its distinctive necessity. $^{30}$

To evaluate this proposal, we need a better understanding of how well these mental operations map onto the standard rules of logic. So let's consider general

\footnotetext{
27 A diverse group of philosophers of logic employs strategies of this general form-for instance, Frege (1893/1903), Hacking (1975), Dummett (1991), and (in more epistemological form) Peacocke (1976).

28 Blackburn's discussion of decisions and decided states has a similar structure (1998, pp. 68-74). In fact, he presents it by drawing on an earlier, unpublished version of Gibbard's (2003) proposal.

29 Though Gibbard (2003, pp. 53-59) only considers combining, rejecting, and generalizing he, presumably, does not intend this to be an exhaustive list of the features that expressivists could take as essential to planning.

30 An expressivist might seek to augment this account of what makes this set of mental operations special by mimicking the "permutation invariance" accounts of logical form found in Tarski (1986) and McGee (1996), and elsewhere.
} 
plans in relation to the rules of logic governing 'all'. ${ }^{31}$ Suppose I make a general plan to believe whatever predictions my guru makes-any prediction he makes, I plan to believe. We can now ask how expressivists explain this 'any'. Gibbard's move (2003, pp. 53-59) is to appeal to a radically idealized notion of planning. On this understanding, general plans are understood to be "maximally complete" instances of planning - one has settled on a course of action for any situation one might be in. But, as we've noted, the expressivists' resources are restricted to appeals to features of our mental lives. So they must explain the maximal completeness of plans as a conceptual completeness-plans that prescribe a course of action for any conceivable situation. ${ }^{32}$ The upshot is that the notion of 'any' associated with my general plan to believe my guru's predications will be a conceptual necessity-anything I could conceive of him predicting, I plan to believe.

However, since the modal features of the meaning postulates for 'all' are, on this account, taken to be a function of the modal features of the basic operations of forming general plans, these postulates will involve a conceptual modality. More specifically, the $\forall$-introduction/elimination rules turn out to be a function of our conceptual capacities in the sense that the scope of, say, $\forall$-introduction is constrained by the sorts of general plans that I could conceive of (e.g., the sorts of things that I can conceive of my guru predicting). This prompts two problems. ${ }^{33}$ First, to the extent that we think that the scope of 'all' is constrained, these constraints do not seems to be a function of the sorts of things that we can conceive of. Worse, the bounds of our conceptual capacities are a function of, among other things, our psychological endowment. But, as we've seen (Sect. 3.1), the move to make the modal profile of logic a function of the modal profile of our psychology does not work-it fails to get the modal profiles associated with logical consequence right. So the appeal to the nature of planning also fails to address the modal test. ${ }^{34}$

\footnotetext{
31 Similar results hold for the relationship between rejecting and ' $\sim$ ' and combining and ' $\&$ '.

32 Gibbard (2003, p. 54) is quite explicit to explaining the completeness of hyperplans as a conceptual completeness. C.f., Blackburn (1998, p. 74, footnote 18).

33 In addition to the concerns that follow in the text, it is worth noting that in wedding themselves to a Stalnaker-Lewis style possible-worlds semantics, expressivists risk inheriting additional problems associated with semantic frameworks of this sort. For instance, a possible worlds account has difficulties making sense of indexical expressions, as well as explaining why, when I believe that $p$, I don't also believe everything entailed by $p$ (see Robbins (2004) for a discussion of these and other problems). Gibbard (2003) and others (e.g., Dreier 1999) acknowledge (some of) these problems and make moves to address them. But it is not obvious the extent to which their efforts are sufficient. To the extent that they're not, the problems with this expressivist proposal are compounded.

34 Objection: The argument in the texts works only if it's not possible to plan for the inconceivable. But it seems we can: one plans for everything one can conceive of, and then one plans for what to do were the inconceivable to occur. So it's wrong to think that the scope of the expressivist's notion of 'all' is too limited to meet the modal test.

Reply: The central assumption of this objection is mistaken. Given what the expressivist takes planning to be, it is not possible to plan for the inconceivable. There are at least two reasons for this. (1) According to the expressivist, for a mental state to be an act of planning, it must rule out possible courses of action; what makes a particular act of planning what it is (e.g., a plan to $\Phi$ and not a plan to $\Psi$ ) is that the planner has ruled out doing certain things. In light of this, consider my plan to flee to my hideout if the inconceivable occurs. When I'm planning for the inconceivable, I must have reason to believe that a particular course of action-like fleeing-will be possible (were this not the case, I couldn't take myself
} 
Let's take stock: Both of the proposals for addressing the modal test through an appeal to features of thought fall short. Though other alternatives may be available, there's good reason to think that they too must fail. Here's why: To address the modal test, expressivists must provide an account of the formal features of thought that can secure the distinctive necessity of logical consequence. But since addressing the modal test involves showing that logical consequence is more stable than other forms of consequence-psychological, rational, etc.- - there is no reason to think that any account grounded in claims about the nature of thought could ever be enough. This is significant for it means that meeting the modal test requires an extra-mental account of logical form.

\subsection{Appeals to an extra-mental account of formality}

Philosophers of logic who take logical form to be part of the world hold that logical terms refer to abstract, formal features of the world. The appeal of this proposal is that, suitably fleshed out, these formal features of the world would have the stable modal profile needed to pass the modal test. Gila Sher offers the most worked out version of this strategy, so I will begin by sketching her account and explaining how it meets the modal test. ${ }^{35}$ I will then demonstrate that an expressivist-friendly version of Sher's proposal cannot be made to work.

Sher holds that the formal features of logic are a subset of the formal properties and objects found in mathematics and set theory. So, for instance, 'and' refers to intersection, 'some' refers to non-emptiness, and 'not' refers to complement. Two features of this account are of note. First, these properties and objects are formal: their essential nature is wholly a function of their structure in the sense that they exemplify regularities or patterns the nature of which does not depend on their substantive content. For example, the property of being a set is a purely structural (and so formal) property in the sense that its essential nature does not depend on what the collected objects are (or even that there are any objects collected).

Footnote 34 continued

to be planning-i.e., ruling something out). However, it's constitutive of "planning" for the inconceivable, that one can have no sense of which options are possible. So I can have no reason to believe that fleeing is possible. So my "plan" to flee cannot be a real plan. (2) As expressions of practical, noncognitive mental states, acts of planning must involve a commitment to act in a certain way: my plan to $\Phi$ expresses my commitment to $\Phi$-ing. So for my plan to flee to my hideout to count as a real plan, it must be psychologically possible for me to commit now to fleeing were the inconceivable to occur. But notice what I'm doing. I'm deciding how to act in a situation about which I can have, by definition, no information. So I'm now committing to flee at some point in the future knowing that-when that time arrives, and I come to know the details of the situation confronting me-I'll surely have no reason to follow my plan. But there's no reason to think such a state is psychologically possible. Notice: the mental state I'd need to be in (committing to a course of action knowing that, come action time, I'll have no reason to follow through) bears a striking resemblance to Kavka's (1983) toxin puzzle (intending to drink a non-fatal toxin an hour from now knowing that, at that time, one will have no reason to fulfill one's intention). What makes Kavka's case paradoxical is that the mental state it purports to describe does not appear to be psychologically possible. This gives us a second reason to deny that it's possible to plan for the inconceivable.

35 See, for instance, Sher (1991, 1999). Wittgenstein (1921) offers an alternative on which, though logical form is part of the world, it is an unanalyzable feature of it. 
It merely requires that there are (possibly empty) collections. Similarly for other set theoretic properties like non-emptiness and intersection: to have the property of non-emptiness just is to have the purely structural feature of being a set containing at least one object; to have the property of intersecting just is to have the purely structural feature of a pair of sets both of which contain some common object(s).

Second, these formal properties and objects are not mental constructions, but rather abstract features of the world; they are the formal (i.e., non-contentful) regularities that can be exemplified by particular concrete objects. Our logical terms refer to these extra-mental formal properties and objects. Sher then argues that these formal properties are related to one another in special, law-like ways. For instance, if the intersection of three sets is non-empty, the intersection of two of those sets must also be non-empty. Furthermore, these law-like relations are special in that they are formal: the relationships they express do not depend on the particular features of the relata, but rather on the mere fact that certain formal properties and objects will evince distinctive regularities or patterns. Because of this, the existence of the formal properties/objects guarantees that certain law-like relations will hold (e.g., the existence of three intersecting, non-empty sets guarantees that any two of those intersecting sets will also be non-empty). ${ }^{36}$

The result is a distinctive account of the nature of logical consequence. Sher's account explains why the sentence

(4) grass is green; therefore, something is green

expresses a logical consequence by taking the logical form of this sentence to correspond to certain formal features of the world, features that are related to one another so as to guarantee that if 'grass is green' is true, 'something is green' must be as well. A more explicit explanation would go like this: To get to the logical form of (4) we begin by expressing it set-theoretically as

(4s) the set of green things contains grass; therefore, the set of green things is non-empty.

We can now make its formal content explicit

(4L) there is a set that contains a particular object; therefore, there is a nonempty set (symbolically, ' $\mathrm{G} a$; therefore $\exists(x) \mathrm{G} x$ ').

With the formal content in hand, we can see that the logical form of this sentence appeals to a set of formal objects. Moreover, these formal objects obey a particular formal law-namely,

(F) Any set containing a particular object must be a non-empty set.

\footnotetext{
36 Sher (1991, Chap. 3) gives a more rigorous explanation and defense of this mathematical conception of formality and its application to logic that appeals to an invariance condition-one that holds that logical constants are structures (e.g., ordered $n$-tuples) that are invariant under all permutations of the domain of objects. While the details of her account are interesting, for present purposes, we can stick with the bare-bones presentation given in the text. Furthermore, though others also seek to explain logical form in terms of invariance (e.g., Tarski 1986; McGee 1996), Sher's account is (to my knowledge) unique in tying invariance to an extra-mental reality.
} 
And so we arrive at our explanation: It's in virtue of this formal law that (4) expresses a logical consequence.

Sher's account is significant because it meets the modal test. Because her proposal identifies the logical terms and the rules of logic with formal properties and laws, logical consequences inherit the underlying modal profiles-profiles that correspond nicely with the distinctive necessity we associate with logic. More specifically, this account gets the modal profile of logical consequence right because it takes the formal properties and objects that are constitutive of logical form to be distinctive formal features of the world; these formal properties and objects exist independently of things like the beliefs or evidence that we have about them. As abstract mathematical entities, they are "removed" from the concrete features of the world in the sense that their essential nature does not depend on what their substantive content happens to be. So things like the facts of human psychology and the laws of physics will not affect their modal profiles.

Sher's proposal works because it identifies logical form with abstract formal features of the world. So, given what we've learned so far, the viability of the expressivists' program turns on their ability to mimic something like Sher's account. This is a substantial challenge: As we've seen, the expressivist takes logic and inference to be ultimately grounded in certain basic features of thought. So he needs to be able to show that mental states can inherit the logical properties of their formal, mind-independent content in a way that is on par with Sher's account of how sentences like (4) inherit their logical properties from their formal content. In recent work, Mark Schroeder develops a sophisticated account of logical consequence on behalf of the expressivist. ${ }^{37}$ However, Schroeder's proposal presupposes that the expressivist has an account of logical form. ${ }^{38}$ But for reasons that are now familiar, we can see that his account does not address the modal test and so must be seen as inadequate. That said, Schroeder's proposal provides tools that will allow us to develop an expressivist-friendly version of Sher's account.

Schroeder observes that we readily accept that some mental states inherit logical properties from their contents. Consider: What's wrong with believing that grass is green and believing that grass is not green? Well, the beliefs are logically inconsistent. $^{39}$ Furthermore, we can explain why these beliefs are logically inconsistent in terms of the inconsistency of their formal content. ${ }^{40}$ That is, it is because the formal content of the belief that grass is green (i.e., that set $\mathrm{G}$ contains object $a$ ) is inconsistent with the formal content of the belief that grass is not green (i.e., that set $\mathrm{G}$ does not contain object $a$ ) that we take the beliefs themselves to be logically inconsistent. Schroeder then notes that what works for cognitive states like

\footnotetext{
37 Schroeder (2008, Chaps. 3-5).

38 See pages 69-70 for an especially clear statement of this assumption. A similar point holds for the recent expressivist account of logical consequence provided in Horgan and Timmons (2006).

39 In what follows, I will for convenience, follow Schroeder in focusing on logical inconsistency rather than logical consequence.

40 The discussion in the text glosses over subtle and interesting features of Schroeder's proposal. For instance, Schroeder shows how we can move from (i) a general notion of inconsistent belief explained in terms of substantive content, to (ii) an account of logically inconsistent beliefs explained in terms of formal content. For simplicity, I focus only on the later.
} 
belief works just as well for certain non-cognitive states like intending. For example, we explain what's wrong with intending to drink the beer, and intending not to drink the beer in terms of the (logical) inconsistency of their (formal) contents. In light of this, Schroeder concludes that it's reasonable for the expressivist to maintain that mental states like believing and intending are like sentences in that they inherit logical properties such as inconsistency from their contents. $^{41}$

However, it's important to recognize that this phenomenon of inheritance is not the result of the formal content alone, but rather a result of the combination of the formal content and the underlying mental state. To see this, notice that-in contrast with believing or intending - there is nothing odd about wondering whether grass is green and wondering whether grass in not green. This means that only certain mental states-beliefs and intentions, but not wonderings - are what Schroeder calls "inconsistency transmitting attitudes," attitudes that are inconsistent when and only when their contents are inconsistent. But so long as at least some non-cognitive states are inconsistency-transmitting (and intentions appear to be), the expressivist seems to have a way of showing how logical properties like inconsistency can be grounded at the level of mental states.

We're now in a position to see how expressivists could make use of Sher's proposal to address the modal test. The idea is this: Sher's account of formal properties and laws provides formal contents with right modal features, and Schroeder's account of inconsistency transmitting attitudes suggests that logical properties can be inherited by certain mental states. By combining these two ideas, the expressivist might have a way to answer the modal test. However, this strategy works only if the relevant mental states (believing, intending) can inherit the modal properties of their contents just like they inherit the inconsistencies of their contents. That is, these states need to be what we might call "modality transmitting attitudes" in addition to being inconsistency transmitting attitudes.

But there's little reason to think this is the case. For starters, the proposal under consideration relies on a dubious assumption. To draw it out, first recall that mental states, as psychological phenomenon, do not have particularly stable modal profiles. Yet the proposal under consideration maintains nonetheless that the formal features of the world are such that they somehow increase the modal stability of our mental states so as to put it on par with that of logical consequences. But such a remarkable feat surely requires explanation. Until we have that, there's no reason to grant the claim of modality transmission to mental states.

But even if such an account could be provided, a further problem remains. Like with inconsistency transmitting attitudes, the expressivist needs it to be the case that only some mental states are modality transmitting. After all, if a mental state like wondering does not combine with formal content so as to inherit logical properties

\footnotetext{
${ }^{41}$ One of the more interesting aspects of Schroeder's proposal is his demonstration that any viable expressivist account of logic must appeal to a single, general, non-cognitive mental state-something he labels "being for". (Schroeder stipulates that being for must be like belief and intention in inheriting logical properties like inconsistency from its contents.) Since nothing in the argument that follows turns on the details of Schroeder's account of being for, I will stick with the more familiar states of belief and intention.
} 
like inconsistency, then how could it inherit the associated modal properties? Because of this the expressivist must be able to demonstrate that the formal features of the world only increase the modal stability of select mental states. How might he do this? Presumably, by following his standard strategy: he will identify the way that a descriptivist like Sher explains how sentences inherit their modal stability, and then seek to mimic this solution at the level of mental states.

Since Sher takes logical terms to refer to formal features of the world, she holds that sentences get their logical form (including the associated modal properties) from the underlying correspondence relations. But merely mimicking a general account of reference will not work for the expressivist, for it doesn't explain why only a select set of mental states inherit the modal properties of their contents. While the expressivist might seek to address this problem by adding some further feature, such a move is not promising. Consider, for instance, an expressivist who took this further feature to be some primitive aspect of mental states like belief and intention. Granted, this would allow him to maintain that only certain mental states are modally transmitting. But it would do so at a high cost. For starters, the move comes off as a particularly ad hoc solution. More significantly, it leaves him in a less theoretically sound position than his descriptivist rival: In addition to needing to mimic the descriptivist's account of correspondence, the expressivist must also add some further (perhaps primitive) feature in order to secure the needed selectivity. In light of this, there is no reason to think that the tools of Sher and Schroeder can secure an expressivist-friendly response to the modal test. ${ }^{42}$

\subsection{The verdict}

The investigation so far demonstrates that neither of the two general strategies for addressing the modal test provide expressivists with the tools needed to develop a viable account of the distinctive necessity that we associate with logical consequences. This conclusion is significant in a number of respects. For one, it draws out an as of yet unrecognized deficiency in the expressivists' explanatory resources-whereas the traditional objections focused on, among other things, whether expressivist accounts could mimic the truth-preserving nature of logical consequences, the argument here demonstrates that expressivists cannot explain a further feature of logical consequences-namely, why they're guaranteed to preserve the truth. Moreover, we've learned that expressivists cannot just accept this failing as a further, minor limitation of their (self-admittedly) revisionist account. For starters, we've seen (Sect. 1) that this guarantee is the most significant feature of logical (as opposed to extra-logical) consequences. Moreover, the discussion of Sher's proposal demonstrates that descriptivists are not similarly constrained. So not

\footnotetext{
42 Might the expressivist do better by seeking to mimic the proposal of Wittgenstein (1921) (see footnote 35)? No. Wittgenstein's proposal answers the modal test by taking logical form to be an unanalyzable feature of the world. As such, it leaves unexplained the very features that the modal test demands one explain. Were no substantive account possible, this move to primitivism might be acceptable. But in the face of Sher's proposal, it is decidedly inferior.
} 
being able to capture it is devastating. The upshot is a new and forceful argument in favor of descriptivist meta-ethical accounts. ${ }^{43}$

\section{Might expressivists gain from a skeptical turn?}

Given that expressivists can't meet the modal test, a last hope would be to try and undermine its validity. Were expressivists able to do this, they could argue that their inability to address the modal test extracts little cost to the overall plausibility of their account. We can find the makings for just this sort of response in Blackburn (1987). ${ }^{44}$ Following this line of argument, expressivists could note that the modal test presumes that we have a good handle on the distinctive necessity associated with logical consequence. But they could then argue that this presumption is mistaken. This claim - if true-would allow the expressivist to set aside the modal test.

In Blackburn's hands, the argument for the second claim takes the form of a Euthyphro-style dilemma (pp. 53-54). Adapting it to the present context gives us the following: The modal test demands an explanation for why logical consequence has the distinctive necessity that it does. But providing such an explanation requires us to analyze the necessity of logical consequence in terms of some fact $M$ about (say) language, rationality, or formal objects. Now either $M$ is itself something necessary, or it isn't. If $M$ is necessary, then we don't really seem to have explained the necessity of logical consequence. Rather, it appears we've just swapped one mysterious modal notion (the necessity of logical consequence) for another (the necessity of $M$ ). But if $M$ is not itself necessary, then there's good reason to think that the necessity of logical consequence "has not been explained or identified, so much as undermined" (p. 53). After all, if the necessity of logical consequence is grounded in something contingent, then it seems we should not conclude that the necessity of logical consequence has been explained, but rather that there's no such necessity! Expressivists could then conclude from this dilemma that the modal test relies on a mistaken conception of what the supposed necessity of logical consequence consists in-it incorrectly presumes that there is some thing, some feature of the world, on which the necessity of logical consequence rests. ${ }^{45}$

\footnotetext{
43 The argument here is significant in another respect. As we noted (Sect. 2), many of the existing critiques of expressivists' alternative account of logic and inference just presume that a descriptivist account of logical form can be given. Seeing that this can be done by adopting Sher's proposal provides these arguments with the further backing that they need.

44 Some of the discussion in Gibbard (2003) suggests that he too might be inclined to a skeptical strategy. For instance, Gibbard (Chap. 4) embraces Horwich's conclusions that logic can be explained without appeal to a robust notion of truth. If he also endorses Horwich's defense of this conclusion, he is committed, with Horwich (1998, pp. 71-76), to endorsing a skeptical strategy.

45 A couple of points: (1) Expressivists might find further support in the arguments of philosophers of logic (e.g., Etchemendy 1990, Brandom 2001) who are skeptical that the traditional strategies for meeting the modal test can be made to work (but see Sher (1996) and MacFarlane (2005) for reasons for thinking this skepticism is misplaced). (2) Expressivists that move to deflate the supposed of necessity of logic would need to provide an explanation of why we have mistakenly thought logic has a distinctive necessity. There are a variety of stories expressivists could tell here-for instance, Blackburn's (1987)
} 
There is something right in this move to skepticism about the modal test. For one, it would be reasonable to hold that the two proposals for addressing the modal test that appealed to features of thought and language fall to the second horn of Blackburn's dilemma. After all, these proposals seek to explain the necessity of logical consequence in terms of semantic notions like truth and satisfaction, or psychological notions of rationality and planning; and we've seen that these foundations are not stable enough to secure the modal profile that we associate with logic. However, this alone is not enough to save the expressivist. Sher's account, after all, does not explain the necessity of logical consequence in terms of something contingent. Rather, Sher answers the modal test by giving a substantive account of formal properties and objects that explains the necessity of logical consequence in terms of the essential features of things like sets and intersection relations. Does this mean her account falls to the first horn of Blackburn's dilemma? Does it mean that her proposal is deficient or trivial as Blackburn's argument would suggest? No. For one, we learn something interesting when we see that the modality associated with logical consequence is of the same sort that we find in mathematics and set theory. But we also see that we can explain the necessity of logic in terms of the more familiar and tractable (structural) necessities of mathematics and set theory. This response shows the descriptivist how to blunt the first horn of Blackburn's dilemma. Furthermore, the explanatory power of Sher's account does much to undermine the hope for an alternative way to give the skeptical turn some bite. $^{46}$

\section{Conclusion}

If the arguments of this essay are sound, then we learn that descriptivists are much better positioned than expressivists to address the modal test. This is significant for several reasons. For starters, as we've seen (Sect. 3.4), it provides both a new argument against expressivist accounts of logic and inference, and a way of shoring existing critiques. More specifically, we see that descriptivists have-at least if they're willing to endorse certain claims about the nature and foundations of logicthe metaphysical and semantic resources they need to give a principled account of logical form, one that explains why logical consequences have the distinctive modal stability that they do. By contrast, the expressivists' commitment to grounding logic and inference in basic features of mental states leaves them unable to effectively mimic this descriptivists' solution. Given that this modal stability is the most

\section{Footnote 45 continued}

projectivism or Brandom's (1994, 2001) pragmatism. So the success of the expressivists' skeptical strategy will turn, in part, on the plausibility of this explanation. Though I won't pursue it here, it is worth noting that the proposals of both Blackburn and Brandom are highly controversial (see, for instance, McDowell 1997; Rosen 1997, 1998; Wright 1988).

46 At this point, an expressivist might protest that the account of formal properties is objectionably nonnatural. However, there are a variety of strategies that a descriptivist can employ to make their account of formal properties consistent with naturalism. See, for instance, Linsky and Zalta (1995) and Maddy (1990). 
distinctive feature of logical (as opposed to extra-logical) consequences, this means descriptivist accounts provide a superior explanation of intuitive difference between the logical and the extra-logical.

While it's true that the argument of this essay requires the descriptivist to endorse controversial claims about the nature and foundation of logic, two points merit emphasis: First, though controversial, these claims are-as Sher's proposal draws out-plausible and explanatorily powerful. Second, as we have seen, the traditional criticisms of the expressivists' alternative accounts of logic presume an ability to distinguish between logical and extra-logical vocabulary. That is, they presume that there is an answer to the modal test. So the descriptivist must be prepared to defend a substantive account of the nature of logic anyway. Sher's proposal allows them to do that. The importance of the modal test for debates in meta-ethics runs deep. ${ }^{47}$

Open Access This article is distributed under the terms of the Creative Commons Attribution Noncommercial License which permits any noncommercial use, distribution, and reproduction in any medium, provided the original author(s) and source are credited.

\section{References}

Aronson, E. (1999). The social animal (8th ed.). New York: Worth Publishers/Freeman.

Blackburn, S. (1984). Spreading the word. Oxford: Oxford University Press.

Blackburn, S. (1987). Morals and modals. In S. Blackburn (Ed.), Essays in quasi-realism. Oxford: Oxford University Press.

Blackburn, S. (1988). Attitudes and contents. In S. Blackburn (Ed.), Essays in quasi-realism. Oxford: Oxford University Press.

Blackburn, S. (1998). Ruling passions: A theory of practical reasoning. Oxford: Clarendon.

Brandom, R. (1994). Making it explicit. Cambridge, MA: Harvard University Press.

Brandom, R. (2001). Articulating reasons. Cambridge, MA: Harvard University Press.

Davidson, D. (1984). Inquiries into truth and interpretation. Oxford: Clarendon.

Dreier, J. (1996). Expressivist embeddings and minimalist truth. Philosophical Studies, 83, $29-51$.

Dreier, J. (1999). Transforming expressivism. Nous, 33(4), 558-572.

Dummett, M. (1991). Logical basis of metaphysics. Cambridge, MA: Harvard University Press.

Etchemendy, J. (1990). The concept of logical consequence. Cambridge, MA: Harvard University Press.

Frege, G. (1893/1903). Grundgesetze der Arithmetik. Jena: Verlag Hermann Pohle, Band I, II. (Partial translation as The basic laws of arithmetic by M. Furth, Ed., 1964, Berkeley: University of California Press.)

Gibbard, A. (1990). Wise choices, apt feelings. Cambridge, MA: Harvard University Press.

Gibbard, A. (2003). Thinking how to live. Cambridge, MA: Harvard University Press.

Hacking, I. (1975). What is logic? Journal of Philosophy, 76(6), 285-319.

Hale, R. (1993). Can there be a logic of attitudes? In J. Haldane \& C. Wright (Eds.), Reality, representation, and projection. Oxford: Oxford University Press.

Horgan, T., \& Timmons, M. (2006). Cognitivist expressivism. In T. Horgan \& M. Timmons (Eds.), Metaethics after Moore. Oxford: Oxford University Press.

Horwich, P. (1994). The essence of expressivism. Analysis, 45, 19-20.

Horwich, P. (1998). Truth (2nd ed.). Oxford: Oxford University Press.

Kavka, G. (1983). The toxin puzzle. Analysis, 44, 33-36.

Linsky, B., \& Zalta, E. (1995). Naturalize Platonism versus Platonism naturalized. Journal of Philosophy, 92(10), 525-555.

\footnotetext{
47 Many thanks to Richard Arneson, David Brink, Nina Brewer-Davis, Jonathan Cohen, Gila Sher, Mark Schroeder, Mike Tiboris and two anonymous referees for their comments on earlier versions of this paper.
} 
MacFarlane, J. (2005). Logical constants. In E. N. Zalta (Ed.), The Stanford encyclopedia of philosophy (Spring 2009 ed.). http://plato.stanford.edu/archives/spr2009/entries/logical-constants.

Maddy, P. (1990). Realism in mathematics. New York: Oxford University Press.

McDowell, J. (1997). Brandom on representation and inference. Philosophy and Phenomenological Research, 57(1), 157-162.

McGee, V. (1996). Logical operations. Journal of Philosophical Logic, 25, 567-580.

Peacocke, C. (1976). What is a logical constant? Journal of Philosophy, 73(9), 221-240.

Quine, W. V. O. (1960). Word and object. Cambridge, MA: MIT Press.

Quine, W. V. O. (1980). Grammar, truth, and logic. In S. Kanger \& S. Öman (Eds.), Philosophy and grammar (pp. 17-28). Dordrecht: Reidel.

Robbins, P. (2004). To structure, or not to structure? Synthese, 139, 55-80.

Rosen, G. (1997). Who makes the rules around here? Philosophy and Phenomenological Research, 57(1), $163-172$.

Rosen, G. (1998). Blackburn's Essays in quasi-realism. Nous, 32(3), 386-405.

Sainsbury, M. (1991). Logical forms. Cambridge, MA: Blackwell.

Schroeder, M. (2008). Being for. Oxford: Oxford University Press.

Schroeder, M. (2009). Hybrid expressivism: Virtues and vices. Ethics, 119, 257-309.

Schueler, G. F. (1988). Modus Ponens and moral realism. Ethics, 98, 501-517.

Sher, G. (1991). The bounds of logic: A generalized viewpoint. Cambridge, MA: MIT Press.

Sher, G. (1996). Did Tarski commit 'Tarski's fallacy'? Journal of Symbolic Logic, 61, 653-686.

Sher, G. (1999). Is logic a theory of the obvious? European Review of Philosophy, 4, 207-238.

Sturgeon, N. (1995). Gibbard's Wise choices, apt feelings. Nous, 29(3), 402-424.

Tarski, A. (1935). The establishment of scientific semantics. In A. Tarski (Ed.), Logic, semantics, mathematics (2nd ed.). Indianapolis, IN: Hacket.

Tarski, A. (1986). What are logical notions? History and Philosophy of Logic, 7, 143-154.

Unwin, N. (2001). Norms and negation: A problem for Gibbard's logic. Philosophical Quarterly, 51, 60-75. van Roojen, M. (1996). Expressivism and irrationality. Philosophical Review, 105(3), 311-335.

Wittgenstein, L. (1921). Tractatus logico-philosophicus. London: Routledge \& Kegan Paul.

Wright, C. (1988). Realism, antirealism, irrealism, quasi-realism. In P. French, T. Uehling, \& H. Wettstein (Eds.), Midwest studies in philosophy, XII. Minneapolis: University of Minnesota Press. 